\title{
IN VITRO EVALUATION OF ROOT CANAL PREPARATION USING OSCILLATORY AND ROTARY SYSTEMS IN FLATTENED ROOT CANALS
}

\author{
Luis Cardoso RASQUIN¹, Fabíola Bastos de CARVALHO², Regina Karla de Pontes LIMA ${ }^{3}$
}

\begin{abstract}
1-DDS, MSc, PhD, Adjunct Professor, Health Department, State University of Feira de Santana, UEFS, Feira de Santana, BA, Brazil; Professor, School of Agrarian Sciences and Health, Metropolitan Union of Education and Culture, UNIME, Salvador, BA, Brazil.

2- DDS, MSc, Professor, School of Agrarian Sciences and Health, Metropolitan Union of Education and Culture, UNIME, Salvador, BA, Brazil.

3- DDS, MSc, Graduate student, Department of Endodontics, State University of São Paulo, UNESP, Araraquara, SP, Brazil.

Corresponding address: Luis Cardoso Rasquin - Rua Oito de Dezembro, 592/ 101, Graça - Salvador - BA - Brazil. Cep.: $40150-000$ - phone: 557132640747 - fax number: 557132671044 - e-mail: lrasquin@ig.com.br
\end{abstract}

Received: October 04, 2006 - Modification: December 15, 2006 - Accepted: January 17, 2007

\begin{abstract}
Q

bjective: The aim of this study was to evaluate the biomechanical preparation of flattened root canals using the following systems: Endo-Eze AET stainless steel oscillatory instruments (Ultradent) and RaCe rotary NiTi instruments (FKG Dentaire). Materials and Methods: Twenty extracted human mandibular incisors were randomly assigned to two groups: Group 1 Instrumentation with oscillatory Endo-Eze AET files (oscillatory technique); Group 2 - Instrumentation with rotary NiTi RaCe files (rotary technique). The teeth were decoronated, had their apices and coronal openings sealed with sticky wax and were embedded in crystal-clear orthophtalic polyester resin. The roots were sectioned transversally with diamond discs at $10 \mathrm{~mm}$ (middle third) and $5 \mathrm{~mm}$ (apical third) from the apex and the segments were reassembled for instrumentation. The sections were photographed before and after root canal instrumentation and evaluated with respect to whether the original root canal shape was modified by instrumentation. To evaluate the differences in the root canal shape before and after biomechanical preparation, scores were given regarding the instruments touch on the intracanal walls. Results: In middle third of the root canals instrumented with the rotary system, there was a change in the original canal anatomy $(p<0.05)$, with formation of a protuberance in the mesiodistal direction. This protuberance did not occur when the oscillatory instrumentation was used. The oscillatory system had better results in the middle and apical thirds as evaluated by Dunn's multiple-comparison test ( $p>0.05$ ). Conclusion: Under the tested conditions, Endo-Eze oscillatory system yielded the instrumentation of all flattened root canal walls, maintaining the canal original shape throughout the biomechanical preparation, and was more effective than RaCe rotary system.
\end{abstract}

Uniterms: Flattened root canal; Root canal preparation; Oscillatory systems; Rotary systems.

\section{INTRODUCTION}

The basic objective of biomechanical preparation consists of pulp tissue removal keeping the apical foramen as tight as possible, developing a gradual tapered shape of the root in a crown-apex direction, with the use of endodontic instruments associated with chemical irrigating substances ${ }^{6}$.

The internal anatomic variations of the root canal system have a role on the success of endodontic therapy. In flattened canals, tissue remnants can persist in recesses and ramifications ${ }^{9}$. According to $\mathrm{Wu}$, et al ${ }^{16}(2000)$ the buccal and lingual extensions of flattened root canals are areas of difficult instrumentation and filling. The success of root canal therapy depends directly on how effectively all phases of the endodontic treatment (i.e., shaping, cleaning, disinfection and obturation) are performed.

Several techniques have been used for biomechanical preparation. However, due to the limitations of conventional techniques in working in curved and flattened canals, some crown-down techniques have been recently investigated in order to provide a more efficient canal preparation. Complete biomechanical preparation with stainless steel instruments involves a high risk of perforating or significantly weakening the root. On the other hand, it seems questionable whether highly flexible $\mathrm{Ni}-\mathrm{Ti}$ instruments allow a controlled preparation of canal extensions ${ }^{12}$.

Ni-Ti rotary instrumentation has been shown to have a limited area of action. Due to their super-elasticity, it is known that NiTi instruments cannot be pressed against the root canal walls, leaving the polar areas of flattened root canals uninstrumented. It is likely that pathogenic microorganisms remain lodged in these areas. Flattened root canals do not allow a great widening of canal diameter without the risk of creating lateral perforations. A change of instrumentation 
techniques should also be considered ${ }^{1}$.

The oscillatory movement or the movement of balanced forces has presented superior results to the filing movements. This movement can be manually executed or can be done using special handpieces that currently have a prominent place in endodontic practice causing a lower incidence of canal transportation and better centralization of the prepared root canal ${ }^{3,7,11,13}$.

The Endo-Eze AET oscillatory system (Anatomic Endodontic Technology - Ultradent, South Jordan, UT, USA) has been recently released to the market with the objective of yielding cleaning and shaping of root canals using the root canal anatomy as a guide and hence preserving the dental structure. This system is comprised of a handpiece that has right-left oscillatory movements at $30^{\circ}$ amplitude, acting in conjunction with stainless steel files ${ }^{14}$.

The purpose of this study was to evaluate the biomechanical preparation of flattened root canals using two different systems: Endo-Eze AET oscillatory system (Ultradent) and RaCe rotary system (FKG Dentaire, LaChaux-de-Fonds, Switzerland).

\section{MATERIALAND METHODS}

\section{Sample}

The research protocol was reviewed by the Ethics in Research Committee of the State University of Feira de Santana (BA, Brazil) and the study design was approved (CAAE-0035.0.059.000-05).

Twenty human mandibular incisors were used in this study. The teeth had a buccolingual distance twice as long as the mesiodistal distance, confirmed by clinical evaluation of the shape of the flattened mesiodistal root, and had been extracted for periodontal reasons and/or extensive caries. The teeth were randomly assigned to two groups: Group 1 Instrumentation with oscillatory Endo-Eze AET files (oscillatory technique); Group 2 - Instrumentation with rotary $\mathrm{NiTi}$ RaCe files (rotary technique).

\section{In vitro Evaluation \\ Preparation of teeth}

The teeth were decoronated with a 40-mm diamond disc (KG Sorensen, São Paulo, SP, Brazil) at the cementoenamel junction. A\#10 stainless steel K-file (Maillefer, Ballaigues, Switzerland) was then passively introduced into the canal until its tip was seen at the apical foramen. The instrument was retracted $1 \mathrm{~mm}$ to determine the working length (WL) by the visual method. Mesiodistal and buccolingual radiographs were taken to confirm the existence of only one root canal.

The teeth had the apices and coronal openings sealed with sticky wax and were placed inside a PVC ring $(25 \mathrm{~mm}$ in diameter; $25 \mathrm{~mm}$ in height) that was filled with crystal-clear orthophtalic polyester resin (Polyfibras - Bahia - Brazil) at a ratio of $10 \%$ monomer per kilogram of resin. The PVC ring had its base perforated to allow the placement of a thread and a screw (FischerÒ MQR 19, Rio de Janeiro, RJ, Brazil) with the purpose of facilitating the removal of the sections for undertaking photographs during the experiment ${ }^{2}$ (Figures $1 \mathrm{a}$ and $1 \mathrm{~b}$ ). The roots were sectioned transversally with diamond discs (Discoflex $40 \mathrm{~mm}$ ) at $10 \mathrm{~mm}$ (middle third) and $5 \mathrm{~mm}$ (apical third) from the apex and the segments were reassembled for instrumentation.

\section{Instrumentation Technique}

In Group 1, the teeth were instrumented using Endo-Eze AET oscillatory system (Ultradent) with Endo-Eze files. The following sequence of instruments belonging to the "Shaping Files" set was used. First, the oscillatory S1 file (yellow shank, D0 $=10 \mathrm{~mm}$, taper $2.5 \%$ ) was used at WL until it became loose into the canal. This file was followed by the SC instrument (red shank, D0 $=13 \mathrm{~mm}$, taper 3.5\%), the $\mathrm{S} 2$ instrument (blue shank, D0 $=13 \mathrm{~mm}$, taper $4.5 \%$ ) and the $\mathrm{S} 3$ instrument (green shank, D0 $=13 \mathrm{~mm}$, taper 6\%). After using the oscillatory files, the apical third was instrumented using manual files belonging to "Apical Files" set of the system (\#15 to \#30).

In Group 2, the teeth were instrumented using RaCe rotary system (FKG Dentaire) according to the crown-down technique in the following sequence: Pre-RaCe 40.08, RaCe $35.02,30.04,30.02,25.04$ and 25.02. Apical preparation was completed with RaCe 25.04 or 30.02 files, depending on root canal anatomy. In this group, all root canals were prepared using a low-speed handpiece (300 rpm) with high-torque motor with torque control (Easy Endo; Easy, Belo Horizonte, MG, Brazill).

The root canal sections were photographed before and after biomechanical preparation. During the instrumentation, the root canals of both groups were irrigated with $5.25 \%$ sodium hypochlorite.

\section{Evaluation of root canal deviation and shape}

Using superimposition of images obtained from magnified and standardized photographs taken before and after biomechanical preparation, the middle and apical thirds were evaluated to determine whether there were changes on root canal original anatomical shape. In order to evaluate the differences between the root canal contours before and after biomechanical preparation, scores were given according to instrument touch on the intracanal walls (Table 1).

\section{Statistical analysis}

The score means were submitted to statistical analysis using the Kruskal-Wallis test $(\mathrm{p}<0.05)$ and Dunn's multiple comparison test.

\section{RESULTS}

Table 2 gives a general overview of the scores attributed after analysis of the photographs taken before and after biomechanical preparation with both tested techniques. In Group 1 (oscillatory technique), one section changed from the original root canal shape in the middle third, that is the 
instrumentation touched only on one wall (score 1), while in the apical third two sections did not maintain the original root canal shape (one section with score 2 and the other with score 1). In Group 2 (rotary technique), six sections had score 2 (the biomechanical preparation produced a circular protuberance in the root canals leaving uninstrumented the isthmus walls) and three sections had score 1 in the middle third (Figure 2). In the apical third, five sections presented change in the original anatomy of the root canal (two sections with score 2 and three sections with score 1) (Figure 3).

In 7 out of 10 mandibular incisors instrumented with the oscillatory system, the biomechanical preparation maintained the original root canal shape up to the working length (Figure 4 and 5). On the other hand, only 1 out of 10 mandibular incisors instrumented with the rotary system maintained the original root canal shape up to the working length.

The statistical analysis showed that the middle third of the root canals instrumented with the rotary system presented a statistically significant change from the original anatomy $(\mathrm{p}<0.05)$, a fact that was not observed in the apical third. With the oscillatory instrumentation, the changes that occurred in the original shape of the canals were not statistically significant.

\section{DISCUSSION}

Root canal instrumentation is one of the most important steps to the success of endodontic treatment and several biomechanical instrumentation techniques have been proposed. However, despite the limitations of the conventional techniques in working in curved and flattened canals, crown-down techniques have been recently proposed with the aim of achieving a more efficient preparation.

The quality of the biomechanical preparation is related to the internal anatomical characteristics of the root canal system $^{1}$. Manual crown-down instrumentation techniques have been more effective in cleaning mesiodistally flattened root canals than rotary techniques.

In this study, the root canals that had mesiodistal flattening and were instrumented with the RaCe rotary system presented changes in their original anatomy with the formation of a protuberance in the mesiodistal direction, leaving the walls of the isthmus uninstrumented. This showed that the rotary instrumentation had a limited working area, in according with previous studies ${ }^{5,10}$.

The flexibility of the NiTi instruments does not allow a controlled instrumentation of the buccal and lingual extensions of flattened canals. These instruments frequently produce a circular protuberance in the root canals,

TABLE 1- Scores attributed to instrument touching on the root canal walls

$\begin{array}{ll}\text { Score } 4 & \text { Touch of the instrument on the four root canal walls } \\ \text { Score } 3 & \text { Touch of the instrument on three root canal walls } \\ \text { Score } 2 & \text { Touch of the instrument on two root canal walls } \\ \text { Score } 1 & \text { Touch of the instrument on one wall of the root canal } \\ \text { Score } 0 & \text { The instrument did not touch any of the root canal walls }\end{array}$

TABLE 2- General distribution of scores

\begin{tabular}{|c|c|c|c|c|c|c|}
\hline & Score 4 & Score 3 & Score 2 & Score 1 & Score 0 & \\
\hline $\begin{array}{l}\text { Oscillatory technique } \\
\text { Middle Third }\end{array}$ & $9^{*}$ & 0 & 0 & 1 & 0 & \\
\hline $\begin{array}{l}\text { Oscillatory technique } \\
\text { Apical Third }\end{array}$ & 8 & 0 & 1 & 1 & 0 & \\
\hline $\begin{array}{l}\text { Rotary technique } \\
\text { Middle Third }\end{array}$ & 1 & 0 & 6 & 3 & 0 & $p<0.05$ \\
\hline $\begin{array}{l}\text { Rotary technique } \\
\text { Apical Third }\end{array}$ & 5 & 0 & 2 & 3 & 0 & \\
\hline
\end{tabular}

\footnotetext{
* Number of sections
} 
maintaining the extensions uninstrumented ${ }^{5,12}$.

Wu and Wesselink ${ }^{15}$ (2001) also demonstrated that, after biomechanical preparation of mandibular incisors with oval root canals using balanced force, $65 \%$ of the canals presented non-instrumented isthmuses.

In the present study, the group instrumented with the rotary system had better results in the apical third, with only two sections having non-instrumented buccal and lingual extensions (isthmuses) versus six middle third sections This may be attributed to the fact that most flattened root canals become more round towards the apex, as previously shown in a study with extracted teeth ${ }^{16}$.

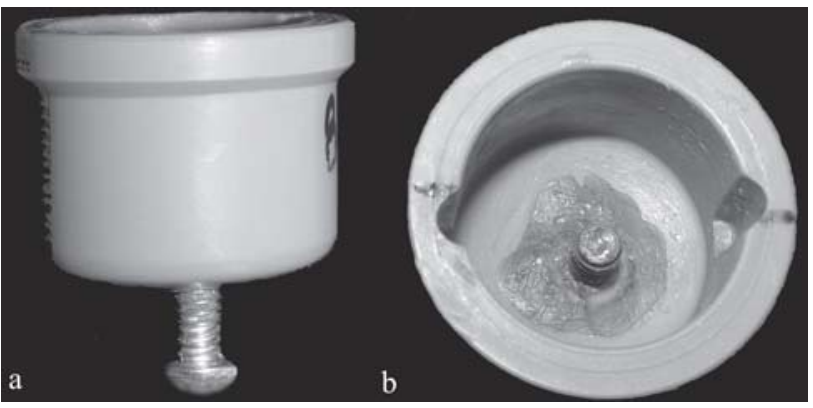

FIGURE 1- Frontal view of the PVC ring (a) and PVC with its base perforated (b)

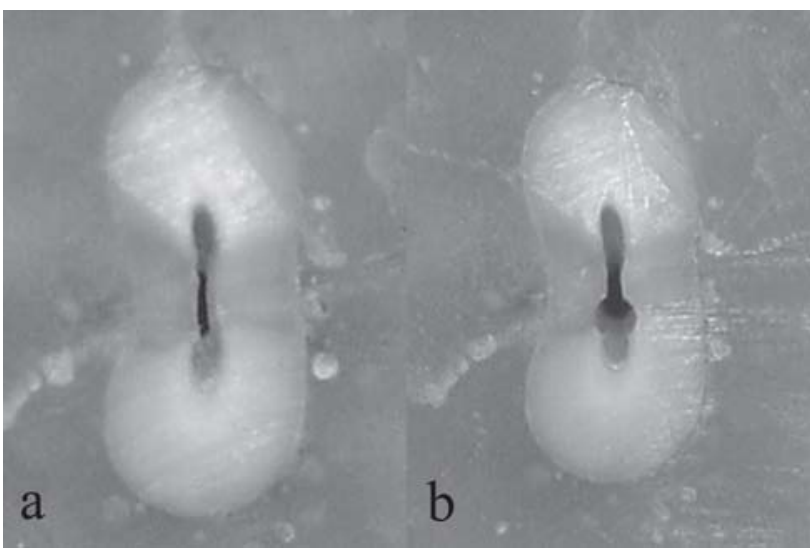

FIGURE 2- Middle third before (a) and after (b) preparation with RaCe system (Score 2)

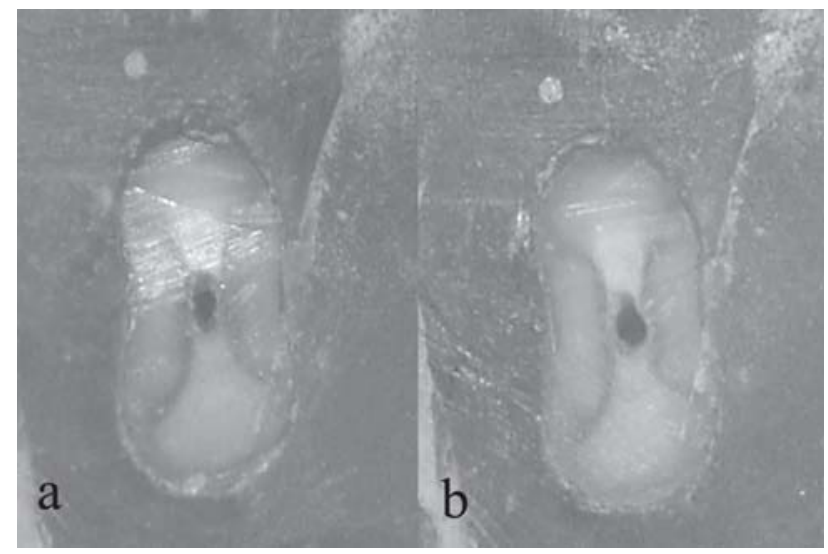

FIGURE 3- Apical third before (a) and after (b) preparation with $\mathrm{RaCe}$ system (Score 2)
Several automated systems that connect different types of files to different handpieces are being introduced to Endodontics. Amongst these are the alternating systems that use oscillatory movements, which have been described as the best type of movement for biomechanical preparation of flattened root canals ${ }^{8}$.

Endo-Eze instruments have recently been introduced to the market and, according to its manufacturer, the use of stainless steel instruments attached to an oscillatory handpiece allows the preparation of oval anatomical irregularities of root canals, thus cleaning the intracanal space without weakening the root.

In this study, the oscillatory system (Endo-Eze) was used in flattened root canals to allow comparisons with the data of previous studies ${ }^{1,10,12}$, which carried out similar studies under the same conditions using similar techniques, but used rotary NiTi instead.

The present study evaluated the amount of uninstrumented root canal area after biomechanical preparation using the oscillatory technique. Our results were better than those of previous studies that used rotary instrumentation in flattened root canals and found that the rotary instrumentation was not capable of reaching all the root canal walls ${ }^{1,10,12}$. In this study, the number of sections that maintained the original root canal shape when using

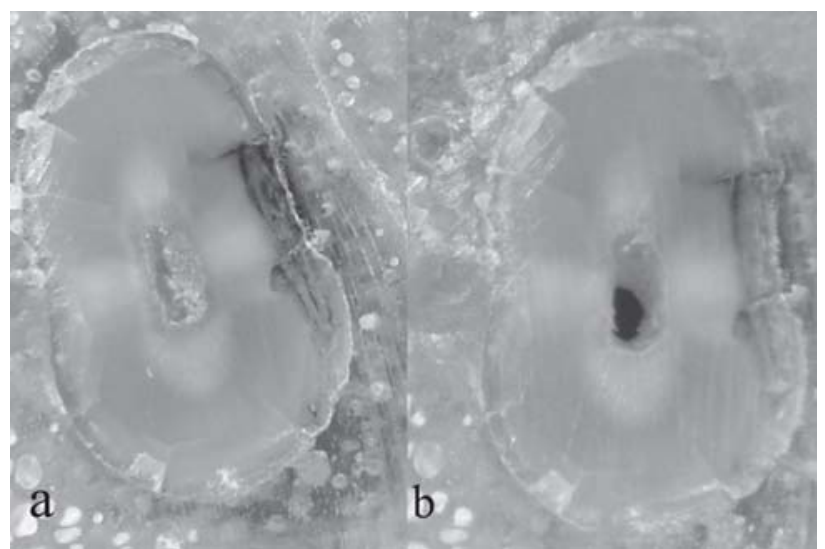

FIGURE 4- Middle third before (a) and after (b) preparation with Endo-Eze system (Score 4)

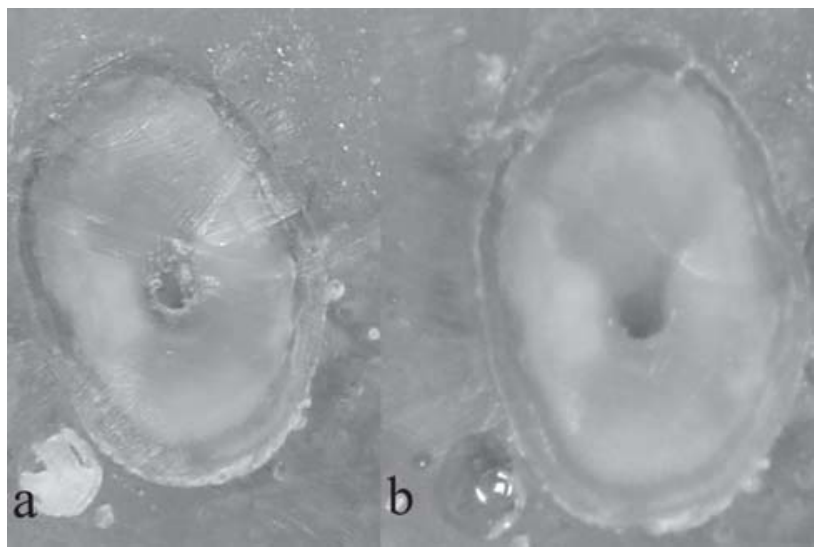

FIGURE 5- Apical third before (a) and after (b) preparation with Endo-Eze system (Score 4) 
the oscillatory technique in middle third was statistically significant ( 9 sections), if compared to the rotary technique (section 1) (Table 2). In the apical third, both techniques maintained the original root canal shape. This result disagree with those of Camargo ${ }^{4}$ (2004), according to whom EndoEze instrumentation caused greater displacement of root canal center than the RaCe instrumentation in the apical third of artificial premolars.

\section{CONCLUSION}

Under the tested conditions, Endo-Eze oscillatory system yielded the instrumentation of all flattened root canal walls, maintaining the canal original shape throughout the biomechanical preparation, and was more effective than $\mathrm{RaCe}$ rotary system.

\section{REFERENCES}

1- Barbizam JVB, Fariniuk LF, Marchesan MA, Pecora JD, SousaNeto MD. Effectiveness of manual and rotary instrumentation techniques for cleaning flattened root canals. J Endod. $2002 ; 28(5): 365-6$.

2- Bramante CM, Berbert A, Borges RPA. A methodology for evaluation of root canal instrumentation. J Endod. 1987;3(5):2435 .

3- Calhoun G, Montgomery S. The effects of four instrumentation techniques on root canal shape. J Endod. 1998;14(6):273-7.

4- Camargo JMP. Estudo comparativo do preparo do canal radicular de dentes artificiais utilizando diferentes técnicas automatizadas de instrumentação [tese]. Araraquara (SP): Faculdade de Odontologia, Universidade Estadual Paulista; 2004.

5- Iqbal MK, Karabucak B, Brown M, Menegazzo E. Effect of modified Hedström files on instrumentation area produced by ProFile instruments in oval canals. Oral Surg Oral Med Oral Pathol Oral Radiol Endod. 2004;98(4):493-8.

6. Leonardo ML, Leal JM. Endodontia: tratamento de canais radiculares. 3. ed. São Paulo: Panamericana; 1998.

7- Limongi O, Ramos IFA, Troian CH, Vanni JR, Albuquerque DS, Barato-Filho F. In vitro analysis of the apical deviation, observed in the proximal sense, produced by two alternated rotation systems: Endo-Gripper and M4. JBE J Bras Endod. 2004;5(16):67-72.

8- Lyon LA, Lopes HP, Lyon JP, Robazza CRC. NiTi and Inox instruments activated by na especial hand piece: apical displacement. Rev Bras Odontol. 2003;60(5):340-2.

9- Marchesan MA, Arruda MP, Silva-Sousa YTC, Saquy PC, Pecora JD, Sousa-Neto MD. Morphometrical analysis of cleaning capacity using nickel-titanium rotary instrumentation associated with irrigating solution in mesiodistal flattened root canals. J Appl Oral Sci. 2003;11(1):55-9.

10- Paqué F, Musch U, Hülsmann M. Comparison of root canal preparation using $\mathrm{RaCe}$ and ProTaper rotary $\mathrm{Ni}-\mathrm{Ti}$ instruments. Int Endod J. 2005;38(1):8-16.

11- Roane JB, Sabala CL, Duncanson MG Junior. The "Balanced force" concept for instrumentation of curved canals. J Endod. 1985;11(5):203-11.
12- Rödig T, Hülsmann M, Mühge M, Schäfers F. Quality of preparation of oval distal root canals in mandibular molars using nickel-titanium instruments. Int Endod J. 2002;35(11):919-28.

13- Royal J, Donnelly J. A comparison of maintenance of canal curvature using balanced forces instrumentation with three different file types. J Endod. 1995;21(6):300-4.

14- Sydney GB, Batista A. Instrumentação não convencional de canais radiculares: sistemas de rotação alternada. In: Leonardo MR. Endodontia: tratamento de canais radiculares. São Paulo: Artes Médicas; 2005. p. 767-85.

15- Wu MK, Wesselink PRA. A primary observation on the preparation and obturation of oval canals. Int Endod J. 2001;34(3):137-41.

16- Wu MK, R'oris A, Barkis D, Wesselink PR. Prevalence and extent of long oval canals in the apical third. Oral Surg Oral Med Oral Pathol Oral Radiol Endod. 2000;89(6):739-43. 